\title{
Der Seelsorger als Leibsorger und als Ärzteschreck
}

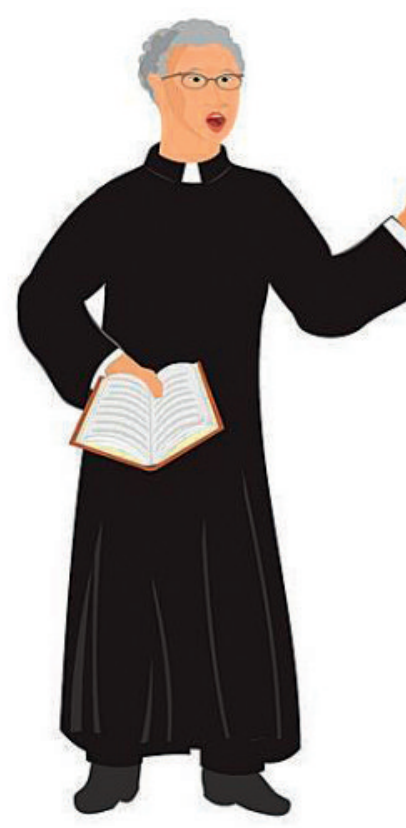

1 Meier L. Schlagwort «Grundversorger-Mangel». Schweiz Ärztezeitung. 2010;91(39):1544-5.

2 Bausinger H. Seelsorger und Leibsorger. Essays über Hebel, Hauff, Mörike, Vischer und Hansjakob. Tübingen: Klöpfer \& Meyer; 2009.

3 Porz R. Ich lasse mich gegen Grippe impfen. Schweiz Ärztezeitung. 2010;91(42):1672

4 Wolff E. Einschneidende Massnahmen. Pockenschutzimpfung und traditionale Gesellschaft im Württemberg des frühen 19. Jahrhunderts. Stuttgart: Steiner; 1998.

5 Danieli E. Der Kalendermacher. Schweiz Ärztezeitung. 2010;91(25):1004.

\section{* PD Dr. Eberhard Wolff ist Kulturwissenschaftler, Medizinhistoriker und Mitglied der Redaktion Geschichte der Schweizeri- schen Ärztezeitung.}

Lukas R. Meier malte in diesem Blatt neulich den Teufel an die Wand: Angesichts des befürchteten Hausarzt-Mangels «scheint sich abzuzeichnen, dass wir

vom ärztezentrierten Gesundheitssystem abwei-

chen (müssen)» [1]. Immer mehr ärztliche Tätigkeiten werden von nichtärztlichem Personal übernommen. MPAs werden $\mathrm{zu}$ «Chronic-CareManagern», Pflegekräfte zu «Advanced-PracticeNurses».

Eine Berufsgruppe wird bei solchen Betrachtungen immer wieder übersehen: die Theologen. «Seelsorger» inszenieren sich gerne als «Leibsorger» und vermengen Heillehren mit Heilslehren. Das zeigen einige Beispiele aus Deutschland. Der evangelische Pfarrer und ehemalige Talkmaster Jürgen Fliege ist als universeller Lebensberater auch in gesundheitlichen Dingen noch immer bekannt. Und dann ist da noch Manfred Lütz, der katholische Theologe und Prediger gegen den «Gesundheitswahn». Aber immerhin ist der auch Arzt.

Äussern sich Theologen gern zu Fragen des körperlichen Leibes? Nehmen wir ein weiteres Beispiel: Friedrich Theodor Vischer. Dem promovierten protestantischen Theologen fiel in seiner Antrittsvorlesung als Professor für Ästhetik und deutsche Literatur an der Universität Tübingen nichts Besseres ein, als eine Lanze für den Universitätssport, das angebliche Stiefkind der Universitäten, zu brechen, denn: «Schönheit aus Stärkung ist zugleich Hebung der Gesundheit, und mit den Gelehrtenkrankheiten, diesem Kreuz der Ärzte, würde es wohl auch anders werden, wenn die Gelehrten nur erst lernten, aufrecht, die Brust heraus, zu gehen.» In den Gelehrten sieht er Schwächlinge, die «den Finger im Reisbrei abbrechen». Es sei ein Ärgernis, «dass am deutschen Beamten und Gelehrten sein Körper wie ein alter Lumpen herunterhängt».

Sie ahnen es zu Recht. Die Berufung Vischers liegt schon einige Zeit zurück. Genauer: Sie datiert auf das Jahr 1844. Vischer (1807-1887) steht im Zusammenhang der Turn- und Gymnastik-Bewegung seiner Zeit. Doch Vischer sieht den durch Gymnastik, Tanzkunst oder Exerzieren gestählten Gelehrtenkörper weniger als Wehrkraft, sondern eher als Garant der Bürgerfreiheit. Denn Vischer ist ein aufmüpfiger Liberaler seiner Zeit, was ihn der Schweizer Leserschaft wohl sympathischer macht. Vischers Auftritt mündete in ein zweijähriges Vorlesungsverbot. Und Pietisten nannten den freigeistigen Theologen einen Gotteslästerer und Götzendiener.

Der emeritierte Tübinger Volkskundler Hermann Bausinger hat in seinem Band «Seelsorger und Leibsorger» [2] einige Beispiele zusammengetragen, in denen sich studierte Theologen und real praktizierende Seelenhirten aus Südwestdeutschland für das körperliche
Wohl ihrer Schäfchen einsetzten. Und damit stellten sie sich immer wieder auch in Opposition zur Ärzteschaft. Der hegelianische Ästhetiker Vischer, so Bausinger, kritisierte etwa damals bereits an der Medizin, «dass ihr sezierender Zugang das Auge beleidige».

In Hagnau bei Meersburg gründete der katholische Pfarrer Heinrich Hansjakob (1837-1916) die erste badische Winzergenossenschaft. Ein Querkopf der anderen Art. Er kämpfte nicht für Gymnastik. Im Gegenteil: das Radfahren über grössere Strecken war für ihn ein «die Gesundheit schädigender Unsinn».

\section{Er trieb die grosse Mehrheit der etablierten Medizin seiner Zeit zur Weissglut}

Hansjakob kämpfte für das Urtümlich-Natürliche der kleinen Leute und gegen eine technische Moderne, wie sie sich etwa in den Dampfschiffen auf dem Bodensee zeigte. Nach Hagnau brachte er ein eben erschienenes Pamphlet gegen die Pockenschutzimpfung mit, die er mit einer ganzen Reihe von Zeitgenossen als unnatürlich und gesundheitsschädlich verdammte. Damit trieb er die grosse Mehrheit der etablierten Medizin seiner Zeit zur Weissglut. Die Frage nach dem Zusammenhang von Impfung und Natürlichkeit, die der Redaktionskollege Porz in dieser Rubrik vor einigen Wochen gestellt hat [3], blickt also auf eine lange Vorgeschichte zurück [4]. Und Impfgegnerschaft war eben auch ein Kulturkampf oft selbstbewusster Bürger und Kleinbürger gegen eine Medizin, die von ihnen als abgehobenes Establishment verstanden wurde.

Die Schweiz kennt einen geistlichen Geistesverwandten von Hansjakob: Den «Kräuterpfarrer» Johann Künzle (1857-1945), der sich seine Berechtigung zur Heilkräuterpraxis gegen die Ärzteschaft 1922 über eine Volksabstimmung in Graubünden erstritt. Und manche erinnern sich wohl noch an den Benediktiner«Kabispater» Thomas Häberle (1912-1997) und sein Buch «Helfen und Heilen» aus den 1970er Jahren.

Bausingers Aufsatzsammlung erzählt auch vom schwäbischen kränklichen Literatenpfarrer Eduard Mörike (1804-1875), der Patientenrechte einforderte, und von seinem alemannischen Kollegen Johann Peter Hebel (1760-1826) [5], wie er die Lust am Rauchen legitimierte. Irgendwie scheinen sich Geistliche gerne gegen die Mediziner oder eine unvergeistigte Medizin auflehnen und behaupten zu wollen.

Eberhard Wolff* 